Difficult Decisions

\title{
When to use insulin in the maturity onset diabetic
}

\author{
R.B. Tattersall and A.R. Scott \\ University Hospital, Clifton Boulevard, Nottingham NG7 2UH, UK.
}

\section{Introduction}

Rational treatment of a disease is only possible if its pathogenesis is known. Diabetes with onset in middle age (here called maturity onset diabetes or MOD) is a complex and probably heterogeneous disorder in which both impaired insulin secretion and insulin resistance can be demonstrated; which is primary and more important is controversial. ${ }^{1}$ The pancreas of patients with MOD may contain $50-80 \%$ of the normal amount of insulin ${ }^{2}$ and it is generally agreed that patients with impaired glucose tolerance (IGT) have normal or even increased circulating insulin levels whereas those with fasting hyperglycaemia always have sub-normal levels compared with age and weight matched controls. ${ }^{3}$ Assuming that IGT is the forerunner of diabetes, one hypothesis holds that the initiating event is insulin resistance; at first insulin secretion is increased and preserves normoglycaemia but eventually pancreatic exhaustion leads to insulin deficiency and a self-perpetuating vicious circle. ${ }^{4}$ Alternatively the primary lesion may be an inherited defect of insulin secretion ${ }^{5}$ which is without clinical consequences until insulin sensitivity is reduced by obesity, age, drugs, illness or other factors. Mathematical modelling by Turner et al. ${ }^{6}$ suggests that nearnormal basal plasma insulin levels can be maintained by hyperglycaemia when beta cell function is deficient and that diabetes only develops when $80 \%$ of beta cell function has been lost. According to this model, insulin resistance alone induces only a small rise in basal plasma glucose which, if beta cell capacity is normal, stimulates a compensatory increase in insulin.

The willingness of the doctor to use insulin in the treatment of MOD will depend on his interpretation of the insulin deficiency-resistance controversy, whether he believes that hyperinsulinaemia is atherogenic and pragmatically whether he thinks his patients will accept injections except as a last resort. Insulin treatment in MOD may be considered under four headings:

Correspondence: R.B. Tattersall M.D., F.R.C.P.

Received: 26 May 1987
(1) Primary treatment at or shortly after diagnosis.

(2) As an alternative to sulphonylureas and/or metformin in primary diet failures.

(3) As alternative or adjunctive treatment for patients whose diabetes remains poorly controlled on maximum doses of tablets.

(4) As a temporary intervention during episodes of poor control or in the treatment of specific diabetic complications.

\section{Insulin as primary treatment}

Nearly a third of cases of insulin-dependent diabetes (IDDM) are diagnosed after age 30 . As in the young, the onset may be dramatic but the progression to insulin dependence is often gradual. Of 154 Finnish patients with onset of non-ketotic diabetes between 35 and 75 years, $14 \%$ were islet cell antibody (ICA) positive. ${ }^{7}$ ICA positive patients were more commonly women, thin, and had auto-immune endocrine disease or thyrogastric antibodies. These patients with 'maturity onset IDDM' have progressive loss of beta cell function and five years after diagnosis $85 \%$ become insulin dependent. ${ }^{8}$ The problem is to identify them early and start insulin before, rather than after a year or two of chronic ill health. It is odd that diabetes is the only endocrine deficiency disease in which measurement of the appropriate hormone is not the key diagnostic test, especially since a peak plasma insulin response during a glucose tolerance test of $18 \mathrm{mU} / 1$ or less together with normal or subnormal body weight predicts virtually all patients who will need insulin within six years. ${ }^{9}$ Clinical features which indicate marked insulin deficiency are severe symptoms, an acute onset, low body weight, a first degree family history of IDDM and, most importantly, ketonuria; these, singly or in combination, correlate well with other markers of IDDM. ${ }^{10,11}$ Even without measuring insulin levels, diabetologists can identify newly diagnosed middle-aged diabetics with insulin deficiency. Retrospectively Laakso et al. ${ }^{12}$ found that 
$78 \%$ of middle aged patients started on insulin at diagnosis had undetectable C-peptide 14 years later. By contrast, of 83 starting insulin more than three years after diagnosis, $75 \%$ had a stimulated C-peptide of $0.6 \mathrm{nmol} / 1$ or more.

\section{Insulin as an alternative to tablets in primary diet failures}

Before 1956, the only treatments for MOD were diet or insulin. Oral hypoglycaemic agents (OHA) were welcomed by doctors and patients and it became accepted that insulin should only be used in MOD after tablets had failed. This policy has no scientific basis ${ }^{13}$ although advertisements often claim 'unique advantages' of OHA over insulin. Thus, tablets are said to be better than insulin because by stimulating endogenous insulin secretion, they result in a 'favourable and physiologic' distribution of insulin between the portal system and periphery ${ }^{14}$ or because, by increasing receptor function, they overcome insulin resistance. ${ }^{15}$ In fact, no proper trial has ever compared tablets and insulin as primary therapy in terms of prevention of complications, preservation of beta-cell function, side effects, patient preference and effect on non-glycaemic aspects of metabolism.

One attempt to do such a study was the University Group Diabetes Program (UGDP), a multicentre trial started in the USA in 1961 to find whether or not control of blood glucose helps to prevent or delay vascular disease'.16,17 At 12 universities over 1000 patients were randomly assigned to placebo, tolbutamide, phenformin or fixed or variable doses of insulin. The trial was cut short because 'diabetics receiving tolbutamide (or phenformin) were more likely to die of cardiovascular causes than untreated diabetics, and insulin was of no value in preventing these'. ${ }^{17}$ Most aspects of this study and its conclusions have been discredited and reanalysis ${ }^{18}$ concluded that 'the variable insulin regimen significantly reduced cardiovascular mortality so that appropriate insulin treatment is highly effective in preventing cardiovascular disease even in relatively mild MOD'. The UGDP study has been so shrouded in controversy that most physicians have simply ignored it. Nevertheless, the basic questions remain and the UK Prospective Study of Therapies of Maturity Onset Diabetes (UKPS) $)^{19,20}$ was started in 1980 to find out if: (1)Better blood glucose control will diminish morbidity and mortality in MOD, and (2) It is better to lower blood glucose with insulin or tablets.

By 1988 the UKPS will have recruited 4000 patients who, if their fasting plasma glucose (FPG) remains over $6 \mathrm{mmol} / 1$ on diet, will be randomized to continue diet or be treated with sulphonylureas, metformin or a basal insulin supplement. The study will end in 1992.
One 'selling point' of sulphonylureas (SU) has been the claim that because they reduce insulin resistance $\frac{O}{2}$ they are more logical than exogenous insulin which in. theory exacerbates insulin resistance by down-regulat $\vec{F}$ ing receptors. This claim has been tested ${ }^{21}$ in कo randomized study to find out whether the magnitude mechanism (receptor or post-receptor) or site (hepaticn or extra-hepatic) of improvement of insulin action differs when patients with MOD are treated with maximally effective doses of either SU or insulines Eight middle-aged overweight patients were treated $\vec{b}$ with tolazamide $1000 \mathrm{mg} /$ day or twice daily lente insulin ( $56 \mathrm{U} /$ day). Both treatments resulted in simila improvement in glucose control and insulin action and it was concluded that 'the choice between insulin and sulphonylureas should be based on factors other than' the expectation that either will uniquely alter insulin action'. Cost may be one factor; a year's treatment with tolazamide $1000 \mathrm{mg}$ daily costs $£ 113$ compared to $£ 139$ for 56 units of Monotard daily plus, say, $£ 5$ foㅉㅀ syringes.

\section{Insulin for treatment of secondary sulphonylurea failures}

How many patients remain well controlled on SŮ్ిñ the long term is unknown since there have been tew prospective studies. Much depends on the definitiorifor failure; if it is not having a normal fasting blood glucose or haemoglobin $A_{1}\left(\mathrm{HbA}_{1}\right)$, most would agre with Schoffling ${ }^{22}$ that after five years $90 \%$ are failures Even by less rigid criteria there are many middle-age $\$$ patients on maximum doses of tablets who claim tofeel well but are poorly controlled. In our clinic, fo윽 example, of 2046 patients not treated with insulin, $35 \%$ have an $\mathrm{HbA}_{1}$ of $11 \%$ or greater (normal range $5.0-8.5 \%$ ) and $24 \%$ a random blood glucose of̂. $16 \mathrm{mmol} / 1$ or more. Thirteen such patients (mean \pm 3 s.d. $\mathrm{HbA}_{1} 12.2 \pm 2.0 \%$ ) on maximum doses of $\mathrm{OHA}$ were recruited to a trial of a new oral hypoglycaemic agent. ${ }^{23}$ When given standard meals on a metabolic unit, mean \pm s.e. peak blood glucose was $22.6 \pm 0.8$ after breakfast, $21.5 \pm 0.8$ after lunch andb $21.1 \pm 0.7 \mathrm{mmol} / \mathrm{l}$ after tea. Yet all had stable weights and no symptoms except tiredness. Standard advice iso that these patients should be changed to insulin with the implication that good control will then be achieved. Unfortunately, most evidence that this is son is anecdotal and uncontrolled. ${ }^{24}$ For example, Selz andu colleagues ${ }^{25}$ changed 11 MODs aged 55-79 years from tablets to insulin because of a 'diminished sense of well-being combined with ill-defined symptoms such as declining physical performance, fatigue, dizziness and pains in the legs'. After one year average 24 hour $_{0}$ glycosuria had not changed but mean FPG fell fromb 16.4 to $10 \mathrm{mmol} / \mathrm{l}$, and was accompanied by betterD 
well-being. We did a prospective randomized crossover study in 58 predominantly non-obese patients on maximum doses of OHA to find out if insulin would improve control or well-being. ${ }^{26}$ Our patients had a mean age of 58 years (range 31-78), a mean duration of diabetes of 9 years, a mean body mass index of $24 \mathrm{~kg} / \mathrm{m}^{2}$ and were given up to 48 units of Monotard once daily in the morning. Glycaemic control was improved by $15 \%$ or more in only 18 patients but 22 felt better of whom only 10 were objectively better controlled. After the study 23 patients chose to continue insulin while 34 returned to tablets. Those who preferred insulin could not be distinguished by age, duration of diabetes, body mass index or any measure of diabetic control. However, there was a tendency for those with the lowest C-peptide levels to do better on insulin. Nearly three-quarters of the 54 patients who completed 6 months on insulin gained weight with a mean increase of 4.2 and a maximum of $13 \mathrm{~kg}$. This is a common experience and many believe that insulin should not be used in fat patients with MOD because the insulin resistance of obesity results in large insulin requirements and further weight gain. ${ }^{27}$ However, two studies in Pima Indians suggest that obesity is not necessarily a contraindication to insulin, but confirm that large doses are needed. ${ }^{28,29}$ In both, patients had a mean body mass index of $43 \mathrm{~kg} / \mathrm{m}^{2}$ and were treated with three times daily Actrapid and Ultralente in a mean daily dose of 198 units (range 99322). All achieved near normal blood glucose in two weeks and had improved insulin secretion and action which lasted two weeks after stopping injections. Most physicians would probably shy away from insulin doses of 200 units a day, if only on the grounds of cost, but these studies suggest that intermittent courses of insulin might restore insulin sensitivity and secretion, albeit temporarily.

A tacit acknowledgement that insulin is not necessarily the ultimate answer in the treatment of OHA failures is the return of combination therapy and a rash of articles with the general title 'Adjuvant treatment with sulphonylurea improves control in patients with MOD poorly controlled on insulin alone'. The studies of Longnecker et al. ${ }^{30}$ and Lardinois et al. ${ }^{31}$ are typical; in the former, 11 patients poorly controlled on 40 or more units of insulin a day had tolazamide added. This significantly (statistically, if not clinically) lowered FPG from 15.1 to $12.3 \mathrm{mmol} / \mathrm{l}$ and increased fasting C-peptide from 0.09 to $0.28 \mathrm{pmol} / \mathrm{ml}$. In the latter study, glibenclamide was added in 14 MOD patients poorly controlled on a mean insulin dose of 40 units/day. After 3 months mean FPG fell from 13.9 to $10.8 \mathrm{mmol} / 1$ but three patients did not improve and only four became well controlled. We conclude that combination therapy does not offer any therapeutic advantage in SU failures compared with insulin monotherapy. Lardinois et al. ${ }^{31}$ argue that the logical approach is simply to use as much insulin as possible, the ultimate presumably being four injections a day or even continuous subcutaneous insulin infusion. It is worth noting that successful weight loss may 'rescue' middle-aged patients who have been poorly controlled on both SU and insulin. Reaven ${ }^{32}$ studied 15 patients over 65 years old who were fat and had FPG consistently above $11 \mathrm{mmol} / \mathrm{l}$ on a mean daily insulin dose of 52 units. Twelve managed, in a combined inand out-patient programme, to lose an average of $9 \mathrm{~kg}$ from a starting weight of $93 \mathrm{~kg}$. FPG fell from 18 to $7.6 \mathrm{mmol} / \mathrm{l}$ and all could be taken off insulin and stabilized on $350 \mathrm{mg}$ chlorpropamide daily.

\section{Insulin as a temporary intervention during periods of poor control or in the treatment of specific diabetic complications}

Insulin is essential for the initial treatment of nonketotic hyperosmolar coma although most patients can then manage on diet alone or SU. Similarly, intercurrent illness or surgery may result in severe hyperglycaemia requiring insulin. Indeed, improved mortality has been claimed for diabetics with acute myocardial infarction receiving intravenous infusion of insulin..$^{33}$ This study, however, used historical controls and the results have yet to be confirmed. Neither insulin treatment nor near-normoglycaemia have been shown to slow or reverse progression of diabetic complications with the possible exceptions of uncontrolled studies in amyotrophy and acute painful neuropathy..$^{34,35}$

\section{Advantages and disadvantages of insulin in MOD}

In general, there is good evidence that near physiological control of blood glucose is beneficial and that 'the goals of therapy should include a serious effort to achieve blood glucose levels as close to those in the non-diabetic state as feasible' ${ }^{36}$ This advice from the American Diabetes Association was only suggested as appropriate for recently diagnosed patients without complications and the full text contains two provisos; first, that the patients' needs and resources must be carefully assessed and the goals individualized and, second, that the shorter life expectancy in older patients may not justify strict control. Unger $^{37}$ has introduced the useful concept that for every patient in whom insulin is being considered one ought to devise an individual optimal risk-benefit ratio which for the patient with MOD would take into account:

\section{(1) Diabetic complications and other illnesses}

Many patients with newly diagnosed MOD already 
have micro or macrovascular complications at diagnosis. ${ }^{38}$ It is also fairly common for MOD with advanced retinopathy to be referred to the diabetologist with the question 'Will better control with insulin reverse retinopathy?' There is no evidence that it will and good reason to think that many with maculopathy have other diabetic complications, poor general health and a limited life expectancy. ${ }^{39}$ In our view, the older the patient and the more severe their complications, the less sense there is in simply treating numbers (either blood glucose or haemoglobin $A_{1}$ ).

\section{(2) Convenience and compliance}

Doctors and non-specialist nurses may have a fatalistic view that older people cannot manage injections. Certainly there may be problems in those who live alone and have shaky hands or poor eyesight but these can often be overcome by getting a relative or neighbour to draw up and inject the insulin or a district nurse to prefill plastic syringes and store then in the refrigerator. Middle-aged patients would prefer to avoid injections but, if a trial of insulin is suggested, compliance is as good or better with injections than with tablets. ${ }^{26,40}$

\section{(3) Hypoglycaemia}

Potential hypoglycaemia must always be a matter of concern in older patients although we know of no evidence that it precipitates strokes or heart attacks. A bigger problem is that repeated hypoglycaemia demoralizes old people and induces panic in their attendants. Hypoglycaemia is probably commoner with insulin than with SU but the risk with the latter is by no means small ${ }^{41}$ and the relative risks of the two have never been formally compared. Attempts to treat MOD with once daily (morning) injections of a longacting insulin often have to be abandoned because of hypoglycaemia; in 1977 we identified 32 patients over 65 years old and found that $44 \%$ on either lente or protamine zinc insulin had had to be changed to twice daily isophane or equivalent because of nocturnal hypoglycaemia. ${ }^{38}$

\section{(4) Weight gain}

As already mentioned, unwanted weight gain is a major drawback to the use of insulin in MOD although the lack of prospective randomized longterm trials comparing insulin and sulphonylureas means that it has never been well documented. In our study of poorly controlled patients with $\mathrm{MOD}^{26}$ the mean weight gain after six months on insulin was $4.2 \mathrm{~kg}$ while in the UK Prospective Study ${ }^{19}$ both insulin and sulphonylureas caused a significant increase in weight after one year, the median being $2 \mathrm{~kg}$ greater than those randomized to diet alone or metformin.

\section{(5) Hyperinsulinaemia}

High peripheral insulin levels may be atherogenic ${ }^{42,4 \frac{43}{0}}$ and there is concern that treatment of MOD witho exogenous insulin might exacerbate the large vesseles disease already present in up to $50 \%$ at diagnosis. Unfortunately, there are few hard facts and it is $\mathrm{a}_{\mathrm{o}}$ matter of opinion whether hyperglycaemia or hyperin-s sulinaemia is more damaging in the long run.

\section{Choosing an insulin regimen}

Choice of insulin regimen will largely be determined byo fashion and the clinician's prejudices. There have been few comparative trials in MOD. However, this + decision is easier if the aim of therapy is defined beforeon starting insulin. This will usually be: (a) relief of symptoms of hyperglycaemia, and/or (b) as nearo perfect control as possible without hypoglycaemia.

The insulin regime in the UKPS is based on theO theory ${ }^{44-46}$ that the predominant abnormality in MOD? is a raised basal plasma glucose due to deficient insulin secretion. Basal insulin supplements correct fasting hyperglycaemia with a minimal risk of hypoglycaenfa ${ }_{\infty}^{\circ}$ which allows the beta cell to function more efficientif... One claimed advantage of this treatment is its si plicity in that the dose of ultralente insulin can be increased until FPG becomes normal and patients monitored in general practice by three monthlyo measurements of FPG and weight. ${ }^{47}$ With this regimen additional short-acting insulin may be unnecessary $\Rightarrow$ because it is claimed that the bulk of glycaemic exposure in mild MOD is from raised basal plasma glucose levels, not postprandial excursions ${ }^{48}$ Originally basal insulin supplements were given with bovine ultralente which, because of its exceptionally long half 3 . life, came nearest to the ideal of a 'peakless' insulin.; The absorption rate $(50 \%$ disappearance time) of 3 . human ultralente is 15 hours compared with 44 hours for bovine ultralente in high doses and 13 compared 3 with 21 hours for small doses. ${ }^{49}$ This still makes humano ultralente more suitable for basal insulin delivery than the intermediate-acting insulins advocated by Riddle ${ }^{50}$ 을 but means that the supplement must be given in the evening. However, our experience (and that of oth- - ) $\mathrm{ers}^{51}$ ) is that even human ultralente before the evening 0 meal or at bedtime rarely achieves 24 hour control of N blood glucose in those who were inadequately con-o trolled on SU. Marked hyperglycaemia is common in the late afternoon and evening and twice daily iso- $\frac{C}{D}$ phane or lente insulin may be better.

In future, biosynthetic human pro-insulin may be ideal for basal insulin delivery since most of itso hypoglycaemic effect results from suppression of 
hepatic glucose output without significant stimulation of glucose disposal. ${ }^{52}$ This would lessen the risk of nocturnal hypoglycaemia and it has been shown that pro-insulin at night in patients with relatively severe hyperglycaemia produced a normal fasting blood glucose within six hours without hypoglycaemia. ${ }^{52}$

If normoglycaemia is a realistic and justifiable goal then addition of pre-prandial soluble insulin to the basal insulin supplement is a flexible alternative in patients willing to tolerate 4 injections a day and selfmonitor blood glucose. With this regime 14 patients with MOD with a mean \pm s.d. HbA $_{1}$ of $14.2 \pm 3.8$ on maximum doses of SU and a high fibre diet achieved an $\mathrm{HbA}_{1}$ of $9.5 \pm 1.1 \%$ and FPG of $7.3 \pm 2.5 \mathrm{mmol} / 1-$ a considerable improvement but still far from 'normoglycaemia' (unpublished observations).

\section{Conclusions}

The treatment of diabetes presenting in middle or old age is not straightforward. Symptoms can always be

\section{References}

1. Weir, G.C. Non insulin-dependent diabetes mellitus: interplay between B-cell inadequacy and insulin resistance. Am J Med 1982, 73: 461-464.

2. Rahier, J., Goebbels, R.M. \& Henquin, J.C. Cellular composition of the human diabetic pancreas. Diabetologia 1983, 24: 366-371.

3. Defronzo, R.A. \& Ferrannini, E. The pathogenesis of non insulin-dependent diabetes. Medicine (Baltimore) 1982, 61: 125-140.

4. Reaven, G. M., Chen, Y-DI, Donner, C.C., Fraze, E. \& Hollenbeck, C.B. How insulin resistant are patients with non insulin-dependent diabetes mellitus? $J$ Clin Endocrinol Metab 1985, 61: 32-36.

5. Cerasi, E., Luft, R. \& Efendic, S. Decreased sensitivity of pancreatic beta cells to glucose in pre-diabetic and diabetic subjects. Diabetes 1972, 21: 224-234.

6. Turner, R.C., Mathews, D., Holman, R.R. \& Peto, J. Relative contributions of insulin deficiency and insulin resistance in maturity-onset diabetes. Lancet 1982, i: 596-598.

7. Groop, L.C., Bottazzo, G.F. \& Doniach, D. Islet cell antibodies identify latent type 1 diabetes in patients aged 35-75 years at diagnosis. Diabetes 1986, 35: 237-241.

8. Irvine, W.J., Sawers, J.S.A., Feek, C.M., Prescott, J.R. \& Duncan, L.P.J. The value of islet cell antibody in predicting secondary failure of oral hypoglycaemic agent therapy in diabetes mellitus. J Clin Lab Immunol 1979, 2: $23-26$.

9. Lyons, T.J., Kennedy, L., Atkinson, A.B., Buchanan, K.D., Hadden, D.R. \& Weaver, J.A. Predicting the need for insulin therapy in late onset (40-69) diabetes mellitus. Diabetic Medicine 1984, 1: 105-107.

10. Kilvert, A., Fitzgerald, M.G., Wright, A.D. \& Nattrass, M. Newly diagnosed insulin-dependent diabetes relieved with diet, tablets or insulin, but normoglycaemia is rarely achieved. Primary insulin treatment is usually reserved for those with marked insulin deficiency and currently there is no evidence that in the rest insulin has any advantages over OHA. Treatment of tablet failures with insulin is justified if there are symptoms (often vague and minimized due to fear of injections). Age is not a contraindication and basal insulin supplements can lower FPG enough to abolish nocturia - a limited but worthwhile goal. A trial of insulin is justified in any patient with MOD who either feels unwell or is poorly controlled. This can easily be done as an outpatient. ${ }^{53}$ To achieve near normoglycaemia in tablet failures, more complex insulin regimes are necessary and benefits have to be weighed against the disadvantages. mellitus in elderly patients. Diabetic Medicine 1984, 1: 115-118.

11. Wilson, R.M., Van Der Minne, P., Deverill, I. et al. Insulin dependence: problems with the classification of 100 consecutive patients. Diabetic Medicine 1985, 2: 167-172.

12. Laakso, M., Sarland, H. \& Pyorala, K. Prevalence of insulin deficiency among initially non insulin-dependent middle-aged diabetic individuals. Diabetes Care 1986, 9: $228-231$.

13. Martin, D.B. Type 2 diabetes: insulin versus oral agents. $N$ Engl J Med 1986, 314: 1314-1315.

14. Garvey, W.T., Olefsky, J.M., Griffin, J., Hamman, R.F. \& Kolterman, O.G. The effect of insulin treatment on insulin secretion and insulin action in type 2 diabetes mellitus. Diabetes 1985, 34: 222-234.

15. Eaton, R.P., Galgan, R., Kaufman, E., Allen, R.C., Russell, L. \& Miller, F. Receptor depletion in diabetes mellitus: correction with therapy. Diabetes Care 1981, 4: 299-304.

16. University Group Diabetes Program. A study of the effects of hypoglycaemic agents on vascular complications in patients with adult-onset diabetes. Diabetes 1976, 25: 1129-1153.

17. University Group Diabetes Program. Evaluation of insulin therapy: final report. Diabetes 1982, 31 (Suppl 5): 1-26.

18. Kilo, C., Miller, J.P. \& Williamson, J.R. The achilles heel of the University Group Diabetes Program. J Am Med Ass 1980, 243: 450-457.

19. UK Prospective Study of Therapies of Maturity Onset Diabetes. The effect of diet, sulphonylurea, insulin or biguanide therapy on fasting plasma glucose and body weight over 1 year. Diabetologia 1983, 24: 404-411. 
20. UK Prospective Diabetes Study 11. Reduction in HbAlc with basal insulin supplement, sulphonylurea or biguanide therapy in maturity onset diabetes. Diabetes 1985, 34: 793-798.

21. Firth, R. G., Bell, P.M. \& Rizza, R.A. Effects of tolazamide and exogenous insulin on insulin action in patients with non insulin-dependent diabetes mellitus. $N$ Engl J Med 1986, 314: 1280-1286.

22. Schoffling, K. Orale diabetes therapie. Acta Endocrinol 1980, 1: 3-18.

23. Scott, A.R. \& Tattersall, R.B. Alpha glucosidase inhibition in the treatment of non insulin-dependent diabetes mellitus. Diabetic Medicine 1987 (in press).

24. Home, $P$. What went wrong? A guide to designing a useful clinical research study before it is too late. Practical Diabetes 1987, 4: 39-43.

25. Selz, B., Nyffenbegger, U. \& Burgi, H. Wann sollen stabile altersdiabetiker auf insulin umgestellt werden? Schweiz Med Wschr 1980, 110: 1534-1537.

26. Peacock, I. \& Tattersall, R.B. The difficult choice of treatment for poorly controlled maturity onset diabetes: tablets or insulin? Br Med J 1984, 288: 1956-1959.

27. Boden, G. Treatment strategies for patients with non insulin-dependent diabetes mellitus. Am J Med 1985, 979 (Suppl 2B): 23-26.

28. Foley, J.E., Kashiwagi, A., Verso, M.A., Reaven, G. \& Andrews, J. Improvement in in-vitro insulin action after one month of insulin therapy in obese non insulindependent diabetics. J Clin Invest 1983, 72: 1901-1909.

29. Andrews, J.J. Insulin therapy in obese non insulindependent diabetes induces improvements in insulin action and secretion that are maintained for two weeks after insulin withdrawal. Diabetes 1984, 33: 634-642.

30. Longnecker, M.P., Elsenhans, V.D., Leiman, S.M., Owen, O.E. \& Boden, G. Combined therapy with insulin and sulphonylurea in non insulin-dependent diabetes mellitus.Arch Int Med 1986, 146: 673-676

31. Lardinois, C.K., Liu, G.C. \& Reaven, G.M. Glyburide in non insulin-dependent diabetes: its therapeutic effect in patients with disease poorly controlled by insulin alone. Arch Int Med 1985, 145: 1028-1032.

32. Reaven, G.M. Beneficial effect of moderate weight loss in older patients with NIDDM poorly controlled with insulin. J Am Geriatric Soc 1985, 33: 93-95.

33. Clark, R.S., English, M., McNeill, G.P. \& Newton, R.W. Effects of intravenous infusion of insulin in diabetes with acute myocardial infarction. $\mathrm{Br}$ Med J 1985, 291: 303-305.

34. Boulton, A.J.M., Drury, J., Clarke, B. \& Ward, J.D. Continuous subcutaneous insulin infusion in the management of painful diabetic neuropathy. Diabetes Care 1982, 5: 386-390.

35. Archer, A.G., Watkins, P.J., Thomas, P.K., Sharma, A.K. \& Payan, J. The natural history of acute painful neuropathy in diabetes mellitus. $J$ Neurol Neurosurg Psych 1983, 46: 491-499.

36. Cahill, G.F., Etzwiler, D.D. \& Freinkel, N. Control and diabetes. $N$ Engl J Med 1976, 294: 1004-1005.

37. Unger, R.H. Meticulous control of diabetes: benefits, risks and precautions. Diabetes 1982, 31: 479-483.

38. Tattersall, R.B. Diabetes in the elderly - a neglected area. Diabetologia 1984, 27: 167-173.

39. Lawson, P.M., Hunt, B. \& Kohner, E.M. Medical condi- $\overrightarrow{\overline{\vec{D}}}$ tions in patients with diabetic maculopathy. Diabetic Medicine 1985, 2: 245-250.

40. Diehl, A.K., Sugarek, N.J. \& Bauer, R.L. Medication compliance in non insulin-dependent diabetes: a randomised comparison of chlorpropamide and insulin. Diabetes Care 1985, 8: 219-223.

41. Asplund, K., Wilholm, B.E. \& Lithner, F. Glibenclamide associated hypoglycaemia: a report on 57 cases. Diabetologia 1983, 24: 412-417.

42. Stout, R.W. Diabetes and atherosclerosis: the role of insulin. Diabetologia 1979, 16: 141-150.

43. Falholt, K., Alberti, K.G.M.M. \& Heding, L. Aorta and muscle metabolism in pigs with peripheral hyperinsulinaemia. Diabetologia 1985, 28: 32-37.

44. Turner, R.C., McCarthy, S.T., Holman, R.R. \& Harr- -

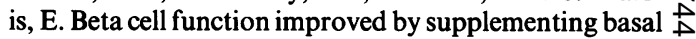
insulin secretion in mild diabetes. $\operatorname{Br} \operatorname{Med} J$ 1976, 1: $\infty$ $1252-1254$.

45. Holman, R.R. \& Turner, R.C. Diabetes: the quest for 음 basal normoglycaemia. Lancet 1977 , i: 469-474.

46. Turner, R.C., Phillips, M.A. \& Ward, E.A. Ultralente based insulin regimens - clinical applications, advantages and disadvantages. Acta Med Scand 1983, 671: 7586.

47. Howe-Davies, S.A., Simpson, R.W. \& Turner, R. \& $\vec{\bullet}$ Control of maturity onset diabetes by monitoring to fasting plasma glucose and body weight. Diabetes Cam 1980, 3: 607-610.

48. Turner, R.C., Mann, J.I., Simpson, R.D., Harris, $\vec{E}$. Maxwell, R. Fasting hyperglycaemia and relatively unimpaired meal responses in mild diabetics. Clin Endocrinol 1977, 6: 253-264.

49. Hilderbrandt, P., Berger, A., Volund, A. \& Kuhl, C. The subcutaneous absorption of human and bovine $\overline{\bar{O}}$ ultralente insulin formulations. Diabetic Medicine 1985, 2: 355-359.

50. Riddle, M.C. New tactics for type 2 diabetes: regimens based on intermediate-acting insulin taken at bedtime. Lancet 1985, i: $192-195$.

51. Ireland, J.T., Wilson, M., Paterson, K.R. \& Reith, S.B.M. Glycaemic control with basal versus bolus insulin therapy in diabetic patients failing to respond to sulphonylureas. In Tattersall, R.B. (ed) Proceedings of the First International Novo Symposium on Non Insulin Dependent Diabetes Mellitus (Type II Diabetes). 1986 Copenhagen, Denmark.

52. Glauber, H.S., Henry, R.R., Wallace, P. et al. The effects of biosynthetic human proinsulin on carbohydrate metabolism in non insulin-dependent diabetes mellitus. $\sigma$ New Engl J Med 1987, 316: 443-449.

53. Wilson, R.M., Clarke, P., Barkes, H., Heller, S.R. \& Tattersall, R.B. Starting insulin treatment as an outpatient: $\omega$ report of 100 consecutive patients followed for a year. JAMA 1986, 256: 877-880. 